\title{
Blood
}

\author{
P.N. Sperryn, MB, FRCP, FACSM
}

Blood contains red and white cells and platelets floating in plasma. The red cell mass of about $2 \mathrm{~L}$ is contained in a total blood volume of about $5 \mathrm{~L}$. Serum is the fluid left after blood plasma clots. The blood's functions include oxygen transport from lungs to tissues in exchange for waste carbon dioxide, transport of hormones, nutrients and waste products between organs, clotting to seal off haemorrhage and the transport of white cells to combat infection.

\section{Blood formation}

Red cells (erythrocytes) are formed from antecedent stem cells in the bone marrow, spleen and lymph nodes and have a limited life of some 120 days. The early red cell, the reticulocyte, is distinctly stainable and a raised reticulocyte count is a sign of increased blood formation, eg after haemorrhage (or blood donation) or treatment of anaemia.

Blood production is controlled by the hormone erythropoietin, mainly secreted by the kidneys, whose renal tubular cells are sensitive to tissue oxygen levels. Erythropoietin acts by stimulating the blood forming stem cells and speeds up red cell formation (erythropoiesis). In addition to iron, red cell production needs vitamin $\mathbf{B}_{12}$, lack of which causes pernicious anaemia and folate, deficiency of which (seen sometimes in pregnancy) causes a similar megaloblastic anaemia. In addition, vitamin $C$ and several trace elements including copper and manganese are needed, as well as thyroxine and androgen hormones.

The red cell contains haemoglobin $(\mathbf{H b})$, a combination of the red ferrous iron-containing pigment haem and a complex protein globin. The globin part comprises four paired polypeptide chains whose structure differs in foetal and adult haemoglobin as $\mathrm{HbF}$ and $\mathrm{HbA}$ respectively.

The haemoglobin molecule changes under the different tissue conditions to load and exchange in turn oxygen and carbon dioxide. The red cell enzyme 2,3diphosphoglycerate (2,3-DPG) increases oxygen $\left(\mathrm{O}_{2}\right)$ release into the tissues and rises within one to two days of high altitude exposure.

Hereditary red cell abnormalities cause destruction by haemolysis, or cell dissolution with consequent anaemia. Common types include:

- G-6-PD deficiency, deficiency of this red cell enzyme, found world-wide but in up to 20 per cent of black Afri- cans, causes haemolysis on exposure to certain drugs, chemicals or foods (eg 'favism' from broad beans).

- thalassaemia, defective $\mathrm{Hb}$ synthesis. Common in Mediterranean peoples, presents as mild trait with mild anaemia and no symptoms or as severe disease with inability to produce normal $\mathrm{Hb}$.

- sickle-cell disorders - a group of haemolytic anaemias in which the abnormal sickle $\mathrm{Hb}$ is found. Common in Afro-Caribbean races and endows some resistance to falciparum malaria. Symptoms include anaemia but also very painful crises in which local infarcts (gangrene) can be precipitated by factors such as chilling, dehydration, or oxygen lack eg flying without adequate pressurization. The full disease is severe but the trait may be unrecognized.

- there are other less common $\mathrm{Hb}$ abnormalities in various ethnic groups.

Intravascular haemolysis occasionally occurs when the red cell is haemolysed in normal capillaries by hard impacts, classically by hard surface foot-strike on the sole or karate punching on the palm. The $\mathrm{Hb}$ thus released into the blood stream is excreted in the pink discoloured urine as haemoglobinuria, to be distinguished from haematuria, in which frank blood is passed in the urine.

The ageing red cell becomes fragile and less efficient and is finally destroyed by the white cell series. This liberates iron and the protein haem which are very efficiently recycled while the residual pigment is excreted via the liver.

\section{Blood tests}

Routine blood investigations start with the haemoglobin test $(\mathbf{H b})$. This dissolves the red cell and measures the concentration of $\mathrm{Hb}$ in the sample, expressing it in grams per $100 \mathrm{ml}$ of blood. The 'normal' range varies between lab samples, but the approximate level of $\mathbf{H b}=13-18 \mathrm{~g} / \mathrm{dl}(100 \mathrm{ml})$ (male) and 11.5-16.5 $\mathrm{g}$ (female). The $\mathrm{Hb}$ is also measured as MCH (Mean Corpuscular $\mathrm{Hb}$ ), an absolute measure of content $\left(\mathrm{MCH}=27-32 \mathrm{pg}\left(10^{-12} \mathrm{~g}\right)\right)$, and $\mathbf{M C H C}$ (Mean Corpuscular $\mathrm{Hb}$ Concentration), ie. overall concentration (MCHC $=30-35 \mathrm{~g} / \mathrm{dl}($ or \%)). A useful clinical test is the Packed Cell Volume (PCV), or Haematocrit, in which the blood is centrifuged so that the denser red cells pack down to form about 45 per cent of the total blood volume in the test tube (range 35-47 per cent female, $40-54$ per cent male).

An excess of red cells in the blood is polycythaemia. It can arise as a reaction to oxygen depletion, for instance in heavy smokers and bronchitics, or mountain dwellers or in athletic altitude training (see below) or, rarely, as a blood disease. 


\section{White blood cells}

These derive from white stem cells in the bone marrow under the influence of chemical factors regulating cell numbers and types in response to changing requirements, including infections and immune system stimuli. The leukaemias are proliferative diseases causing excessive white cell growth.

Polymorphonuclear leucocytes (polymorphs, or granulocytes) are classified by their staining response into neutrophils, eosinophils and basophils. Neutrophils engulf infective organisms. Their lysozyme is released during ingestion of bacteria and helps kill these organisms. The resulting pus itself stimulates new white cell production (hence the raised white cell count, or WBC, in infection). They have a short life in the bloodstream and spend some time attached to the blood vessel walls whence they may be returned to the bloodstream by stress, emotion or exercise. Eosinophils respond to foreign proteins such as parasitic infestations, antigens, or antigen-antibody complexes, hence the high eosinophil count, or eosinophilia, in asthma, allergies and worm infections. Basophils release histamine in immediate hypersensitivity reactions caused by allergy.

\section{Platelets and clotting}

Platelets fragment off from large bone marrow precursor cells. They stick to blood vessel injuries, attract more platelets by aggregation and initiate release of blood clotting factors such as thromboxane.

Clotting is a complex chain reaction precipitated by vessel wall damage. Initial vessel spasm tends to diminish blood loss. The phased release of clotting factors brings about coagulation, or clotting. While platelets are prevented from adhering to intact vessel walls by the natural anticoagulant prostacyclin, tissue damage immediately precipitates clotting mechanisms to plug the haemorrhage. Thus damage causes platelet adhesion, prostaglandin and thromboxane release (from platelet arachidonic acid), as well as fibrinogen secretion. This leads to formation of fibrin and capillary plugging. This fibrin plug is not a true clot. Aspirin decreases platelet adhesiveness, leading to anticoagulant effects.

Coagulation follows plugging as the full cascade of clotting reactions comes into play. A number of clotting factors are released by tissue damage, including Factor VIII (AHG, or Anti-Haemophilic Globulin). The chain reaction proceeds with the conversion of prothrombin to thrombin and, by thrombin's action, fibrinogen to fibrin and clot formation.

Clots can be dissolved by fibrinolysis, tissue plasminogen being activated into fibrin-digesting plasmin. The drug, streptokinase, promotes this reaction, dissolving clots. Exercise enhances fibrinolysis, i.e. counteracts clotting.

Clotting is prevented by deficiency of any coagulation factors, eg haemophilia due to AHG deficiency, and by the use of anticoagulant drugs such as warfarin or heparin (and aspirin).

\section{Anaemia}

Anaemia is defined as the state in which the $\mathrm{Hb}$ is below the accepted norms for the individual's age, sex and location. It can be due to blood loss (eg haemorrhage, menstrual periods, ulcers), infestations (eg worms), many illnesses, and failures of normal blood development, including blood and endocrine disorders, drugs and deficiency of essential blood components - especially iron, vitamin $B_{12}$ and folate. The commonest anaemia is due to iron deficiency. Very strict vegetarians (vegans) are at risk of $B_{12}$ deficiency.

\section{Iron deficiency anaemia}

The average daily iron requirement is about $1 \mathrm{mg}$ to cover essential tissue and sweat loss, plus an average $1 \mathrm{mg}$ to cover menstrual loss, plus about $2.5 \mathrm{mg}$ daily in pregnancy and lactation. Inadequate diet through poverty or faddism easily leads to iron deficiency.

Symptoms depend on the rate of onset of anaemia and include undue fatigue, lethargy and breathlessness. Athletes may suffer gradual loss of form and energy. The range of 'normal' $\mathrm{Hb}$, however, may make it difficult to assess minor degrees of anaemia. A 'low' $\mathrm{Hb}$ for a male may be 'normal' for a female, but many females suffer chronic mild iron deficiency unawares because of menstrual loss and inappropriate dieting. It is wise to monitor the $\mathrm{Hb}$ regularly in all female athletes in heavy training.

\section{Athletes anaemia}

Haemoglobin levels may be misinterpreted in highly trained athletes when blood dilution occurs as a result of heavy work loads. This is described in detail in an accompanying review article (page 000). While it is important to keep female athletes' blood counts under review and many, if not most, may benefit from regular iron supplements, it is essential to realize that pumping athletes with excess iron or other blood components is not only pointless, but can be counterproductive. The body's blood forming mechanisms are extremely finely controlled and 'extra' blood cannot be made in this way. Excessive iron intake may cause bowel symptoms - either constipation or diarrhoea.

\section{Blood supplementation}

A full complement of red cells and $\mathrm{Hb}$ provide the maximum oxygen carriage to the exercising muscles. Hence the reasoning that supplementary blood may do even better. To some extent this is true. The review article (page 000) covers this topic in detail. In essence there are four ways in which the blood could be supplemented.

(1) supplementing the diet with blood forming factors. This simply does not work, beyond rectifying pre-existing disease or deficiency.

(2) altitude training stimulates extra red cell production in response to the lower oxygen content of the atmosphere. Muscle myoglobin may also be enhanced by careful use of altitude stimulus. Red cells are formed, but changes in blood viscosity and the difficulty of training hard at medium $(2000 \mathrm{~m})$ or higher altitudes make this a sometimes hazardous venture. Some athletes simply cannot compensate for altitude and can fail disastrously, others find it difficult to return reliably to sea level because of the locomotor detraining effect. This describes the discrepancy between the altitude stressed heart, lungs and blood and 
the inevitably seriously undertrained muscles. Timing is all-important: altitude training should never be tried for the first time before serious competition and adequate time must be allowed for refinding 'sea-level legs'. High altitude-born athletes keep a life-long advantage in these compensatory mechanisms.

(3) in blood doping, or autoretransfusion, some of the athlete's own blood is removed, stored and retransfused in time for competition; in the meanwhile the athlete has copied the mechanism which compensates for haemorrhage and made new red cells. This only takes him back to his normal $\mathrm{Hb}$. The technical disadvantages of blood doping include transfusion errors (which can kill by infection or accidental mismatch) and suboptimal blood preservation and storage - which by retransfusing dead red cells would invalidate the whole procedure. At best, the technique can only use a cross-section of red cells - old, new and indifferent and many will inevitably decay or be lost in transfer. Also, the retransfused red cells increase the blood's viscosity or stickiness, thus slowing the circulation and negating the advantage of initially higher oxygen levels. The technique certainly can give benefit under perfect management and is still difficult to detect reliably, certainly without repeated blood tests which measure (un)natural levels of the blood-forming hormone erythropoietin (see above).

(4) the future beckons with the possibility of cheap injections of genetically-engineered erythryopoietin truly hyperstimulating the marrow into extra red cell production. Apart from ethical considerations and any disadvantages which may emerge - this would certainly eliminate the dangerous menace of transfusions. 